\title{
ENVIRONMENTAL DEGRADATION OF DISSIMILAR AUSTENITIC 316L AND DUPLEX 2205 STAINLESS STEELS WELDED JOINTS
}

\begin{abstract}
The paper describes structure and properties of dissimilar stainless steels welded joints between duplex 2205 and austenitic $316 \mathrm{~L}$ steels. Investigations were focused on environmentally assisted cracking of welded joints. The susceptibility to stress corrosion cracking (SCC) and hydrogen embrittlement was determined in slow strain rate tests (SSRT) with the strain rate of $2.2 \times 10^{-6} \mathrm{~s}^{-1}$. Chloride-inducted SCC was determined in the $35 \%$ boiling water solution of $\mathrm{MgCl}_{2}$ environment at $125^{\circ} \mathrm{C}$. Hydrogen assisted $\mathrm{SCC}$ tests were performed in synthetic sea water under cathodic polarization condition. It was shown that place of the lowest resistance to chloride stress corrosion cracking is heat affected zone at duplex steel side of dissimilar joins. That phenomenon was connected with undesirable structure of HAZ comprising of large fractions of ferrite grains with acicular austenite phase. Hydrogen assisted SCC tests showed significant reduction in ductility of duplex 2205 steel while austenitic 316L steel remains almost immune to degradation processes. SSR tests of dissimilar welded joints revealed a fracture in the area of austenitic steel.
\end{abstract}

Keywords: duplex steel 2205, austenitic steel 316L, welded joints, stress corrosion cracking (SCC), hydrogen embrittlement

\section{Introduction}

Duplex stainless steels (DSS) are modern structural materials with good corrosion resistance and enhanced mechanical properties which have been developed as an attractive technoeconomical substitute to austenitic grades. The high yield strength of duplex steels ( $>450 \mathrm{MPa})$ enables the plate thickness of the construction to be reduced considerably. For this reason, these steels are increasingly used for marine and offshore elements like tanks and pipelines that come into direct contact witch salt water or other corrosive media. It often happens that the older structures made of austenitic stainless steels must be combined with elements made of duplex steels. Such dissimilar welded joints of stainless steels can be a weak point of whole construction $[1,2,3]$.

Weldability of austenitic stainless steel is considered as good. It is necessary to choose consumables that can give 5 to $10 \%$ of delta ferrite in the welded metal microstructure that is essential to prevent solidification cracking. The extensive precipitation of brittle phases in weld metal can be another problem when too slow cooling is applied. The heat input is therefore normally restricted to a maximum of $1.5 \mathrm{~kJ} / \mathrm{mm}$ and the interpass temperature limited to $100^{\circ} \mathrm{C}$. Directions for welding technologies indicate that excessive dilution with the base metal should be avoided. More problems can occur when welding a duplex steel. Arc welding operation gives more or less undesired heat treatment of the area close to the weld and can change fine microstructure of ferrite and austenite in roughly equal proportions that is characteristic for base material. During welding the heat affected zone (HAZ) is brought to a temperature, where the material is almost fully ferritic. Upon cooling, a reformation of austenite takes place. When cooling is rapid, high ferrite content can remain in the HAZ. On the other hand, when welding heat input is too high, precipitation of harmful intermetallic phases can occur. This can significantly reduce mechanical properties and corrosion resistance of welded joints. To maintain acceptable properties of the joints, the ferrite content in weld metal and heat affected zone should be in the range $25-70 \%$ [4-6].

Certain problems can arise when dissimilar austeniticduplex welds are performed, mainly due to the dilution of welded steels and weld metal and microstructural changes at the HAZ on the botch sides of the weld. Presented structural changes within the welded joints of austenitic and duplex stainless steels have a significant impact on the corrosion resistance of the dissimilar joints, especially to stress corrosion cracking. Corrosion resistance of weld metal, parent materials, and heat affected zones on both sides of the weld should be considering. Stress corrosion cracking is probably the most serious form of corrosion in industrial processes. This is a very common problem for austenitic grades when water is used for the cooling process. The risk of SCC can be eliminated with the use of more resistant materials such as high nickel alloys or duplex stainless steels.

\footnotetext{
* INSTITUTE OF ENGINEERING MATERIALS AND BIOMATERIALS, SILESIAN UNIVERSITY OF TECHNOLOGY, 18A KONARSKIEGO STR., 44-100 GLIWICE, POLAND

** DEPARTMENT OF MATERIALS AND WELDING ENGINEERING, GDAŃSK UNIVERSITY OF TECHNOLOGY, 11/12G. NARUTOWICZA STR., 80-233 GDAŃSK, POLAND

\# Corresponding author: santina.topolska@polsl.pl
} 
While the austenitic steels in many cases become resistant at Ni levels above $26 \%$, the duplex alloys will have the same or higher resistance at much lower alloying levels due to the dualphase structure.

Hydrogen degradation is one of the causes of premature failure of steel constructions and generates large losses in many industrial areas. Unexpected failures have been observed in marine and offshore cathodic protected constructions. Hydrogen charging occurring as a part of cathodic protection has been shown to be enough to produce hydrogen embrittlement (HE) of steels. According to the literature $[7,8]$ ferritic stainless steels are clearly susceptible to HE while austenitic stainless steels in general exhibit less signs of HE. The resistance to HE of duplex stainless steels falls in between the resistance the ferritic and austenitic stainless steels.

Environmentally assisted cracking susceptibility of dissimilar welded joints was assessed in slow strain rate tests (SSRT). The basic problem that had to be explained in this investigations was to reveal whether the environmental impact of chlorides or anodic polarization will change the behavior of the joints during tensile test. Slow strain rate tests of such joints in an inert environment always end up breaking in the material of lower strength, i.e. $316 \mathrm{~L}$ steel. It is not known whether structural changes in the weld metal and in the HAZ of the weld will affect corrosion resistance and consequently weaken the strength enough to cause cracking in these areas.

\section{Experimental}

The plates $15 \mathrm{~mm}$ in thickness made of UR45N+(1.4462) duplex stainless steel and AISI 316L (1.4432) austenitic stainless steel were used. Chemical compositions of the steel plates are presented in Table 1.

TABLE 1

Chemical composition of 2205 and 316L stainless steels

\begin{tabular}{|c|c|c|c|c|c|c|c|}
\hline \hline \multicolumn{7}{|c|}{ Content of chemical elements (\% mass) } \\
\hline & $\mathbf{C}$ & $\mathbf{S i}$ & $\mathbf{M n}$ & $\mathbf{C r}$ & $\mathbf{N i}$ & $\mathbf{M o}$ & $\mathbf{N}$ \\
\hline $\mathrm{UR} 45 \mathrm{~N}+$ & 0.017 & 0.40 & 1.5 & 21.9 & 5.7 & 3.0 & 0.16 \\
\hline $316 \mathrm{~L}$ & 0.019 & 0.38 & 1.7 & 16.0 & 11.0 & 2.5 & 0.04 \\
\hline
\end{tabular}

Butt joint was performed with the use of high performance - submerged arc welding (SAW) method instead of currently employed gas metal arc welding (GMAW) method. The parameters used for welding process are listed in Table 2 . The welded joint was performed using $2 \mathrm{Y}$ square edge preparation (Fig. 1). The duplex stainless steel filler metal $22 \mathrm{Cr}-9 \mathrm{Ni}-3 \mathrm{Mo}$ (wire of $\phi 3,2 \mathrm{~mm}$ ) and basic non-alloyed agglomerated flux (ESAB Flux 10.93) were used. Two beds were performed to fill the whole joint with the use of heat inputs of 2.4 and $3.4 \mathrm{~kJ} / \mathrm{mm}$. The interpass temperature was limited to $100^{\circ} \mathrm{C}$ maximum. The double sided, two pass welding process for duplex and austenitic thick plates is considered to be undesirable, as the required high heat input would generate too low a ferrite content in the weld metal and create favorable conditions for the precipitation of intermetallic phases [9]. Other opinions [10] say that thick plates of stainless steels can be successfully welded with the use of higher heat inputs. So far there is not clearly established the maximum heat input limit that gives joints with acceptable mechanical and corrosion properties. Welded plate was X-rayed and crack tested, and found to be satisfactory with B quality class according to EN 25817 standard.

TABLE 2

Applied welding parameters used for weld preparation

\begin{tabular}{|c|c|c|c|c|c|}
\hline \hline Bead & $\begin{array}{c}\text { Current } \\
{[\mathbf{A}]}\end{array}$ & $\begin{array}{c}\text { Voltage } \\
{[\mathbf{V}]}\end{array}$ & $\begin{array}{c}\text { Current } \\
\text { polarity }\end{array}$ & $\begin{array}{c}\text { Welding speed } \\
{\left[\mathbf{c m} \cdot \mathbf{m i n}^{-\mathbf{1}}\right]}\end{array}$ & $\begin{array}{c}\text { Heat input } \\
{\left[\mathbf{k J} \cdot \mathbf{m m}^{-\mathbf{1}}\right]}\end{array}$ \\
\hline 1 & $460-500$ & 32 & $\mathrm{DC}(+)$ & $38-40$ & 2.4 \\
\hline 2 & $560-580$ & 33 & $\mathrm{DC}(+)$ & 30 & 3.48 \\
\hline
\end{tabular}

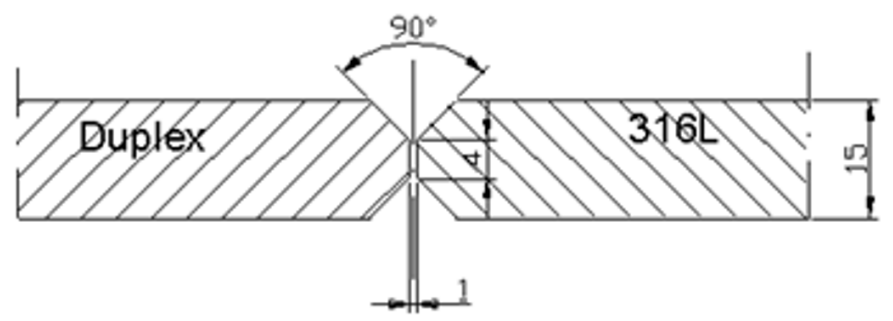

Fig. 1. Edge preparation for dissimilar welded joint

\section{Results and discussion}

\subsection{Metallographic examinations}

Metallographic examinations were aimed to determine the general microstructure of the weld metal and heat affected zones. Microscopic observations were performed to find phase ratio of austenite and ferrite, the presence of secondary austenite and precipitations of any intermetallic phases. Phases were identified by the color contrast etching produced by Berah reagent $\left(\mathrm{HCl}+\mathrm{K}_{2} \mathrm{~S}_{2} \mathrm{O}_{4}\right)$.

Figure 2 shows not uniform microstructure of the welded metal. Primary ferrite dendrites are visible as columnar grains developed in fast cooling conditions oriented in accordance with the heat flow. Subsequent ferrite transformation created boundary austenite (GBA) and inter-granular austenite (IGA), Fig. 3a. In

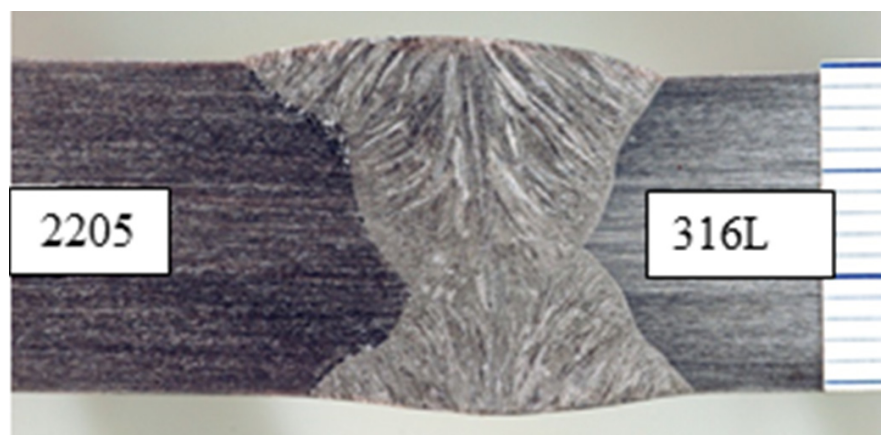

Fig. 2. Macrostructure of dissimilar 2205-316L welded joint 
a)

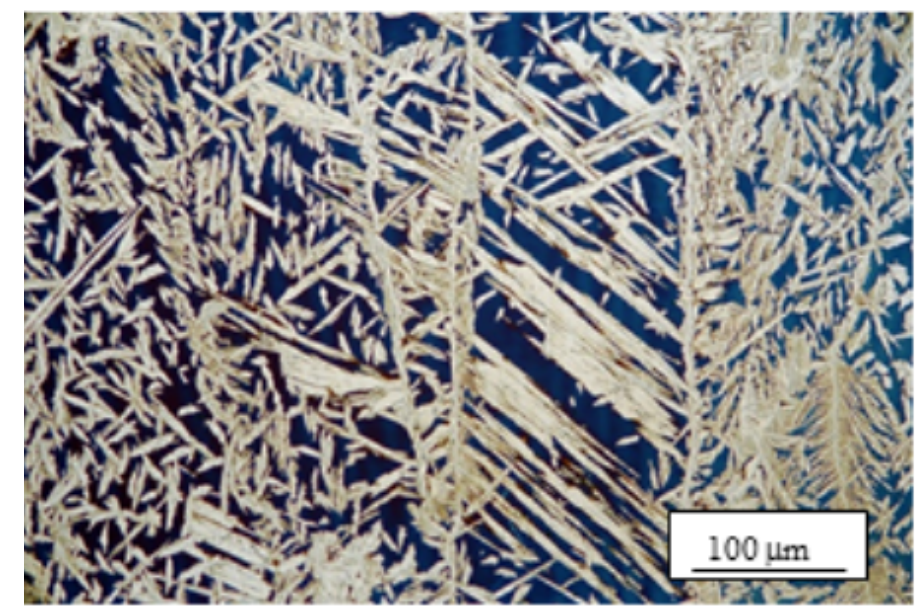

b)

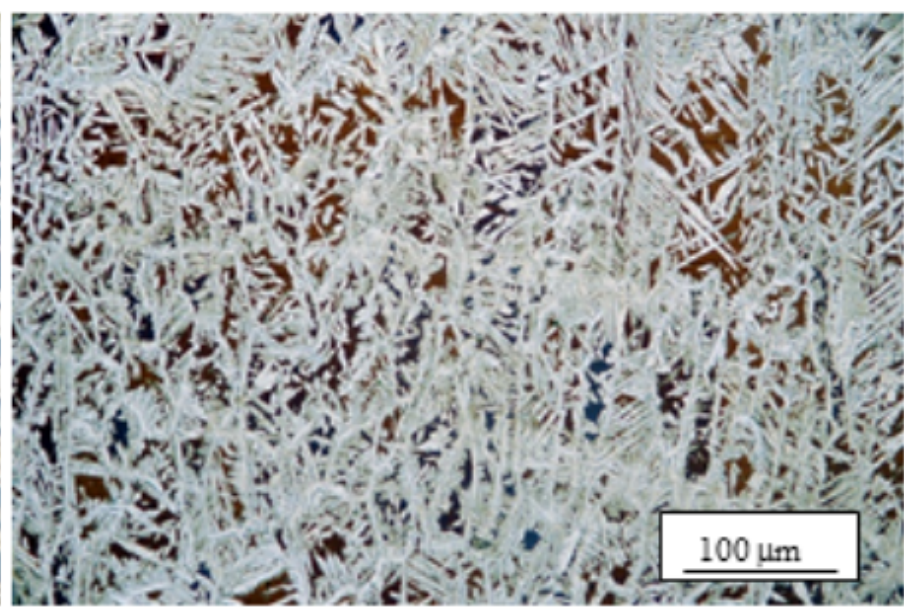

Fig. 3. Microstructure of the welded metal. a) face of the joint, b) centerline

the face of the weld a greater share of ferrite is visible. More globular austenite was observed in root area of the first bead. This area was reheated by second bead and secondary austenite $\left(\gamma_{2}\right)$ created decreasing the proportion of the ferrite, Fig. $3 \mathrm{~b}$.

The heat affected zone microstructure could be critical for welded joint properties [11-13]. For the examined weld the very narrow zone of about 200-350 $\mu \mathrm{m}$ were observed on the duplex steel side (Fig. 4). The ferrite content in that zone was significantly higher in comparison to the parent material of 2205 duplex steel and reach about $70 \%$. The HAZ microstructure consists of lamellar austenite precipitates located mainly on equiaxial great ferrite grain boundaries and in a minor amount inside the ferrite grains. There was no evidence of secondary phases in the HAZ microstructure.

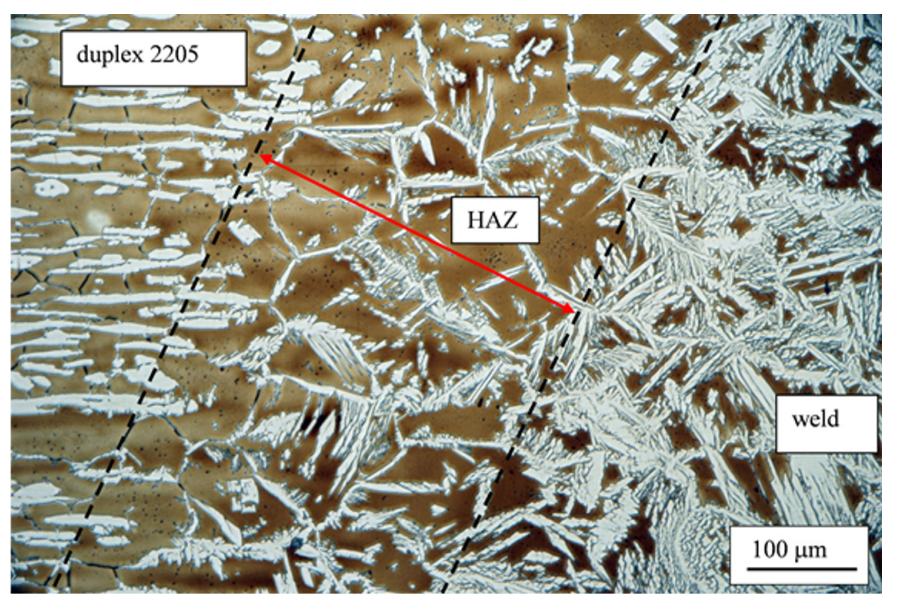

Fig. 4. Heat affected zone microstructure. Duplex steel side

The width of heat affected zones from the $316 \mathrm{~L}$ steel side (Fig. 5) was extremely narrow and reach 100-150 mm. The microstructure consists of lamellar ferrite precipitates that surround austenite grains. The ferrite content in this zone reaches $25 \%$. There was no evidence of excessive austenite grain growth and no signs of cracks.

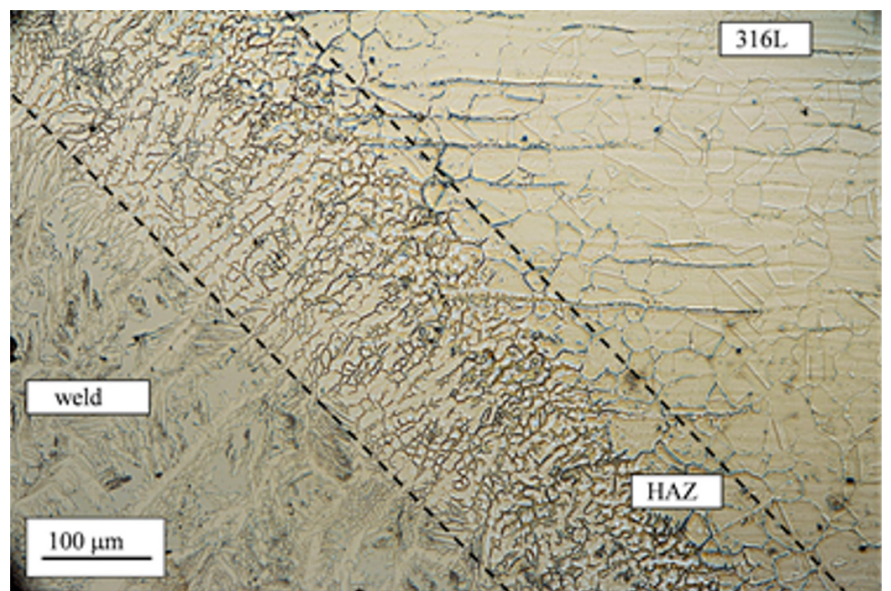

Fig. 5. Heat affected zone microstructure, 316L steel side

\subsection{Chloride stress corrosion cracking}

The susceptibility to stress corrosion cracking was determined in slow strain rate tests with the strain rate of $2.2 \times 10^{-6} \mathrm{~s}^{-1}$. Tests were carried out on samples taken from parent materials of duplex 2205 and AISI 316 steels and samples from the welded joint. The gauge section of specimens contains whole welded joint that means the weld metal, heat affected zones and parent materials. The shape and dimensions of specimens are shown in Fig. 6.

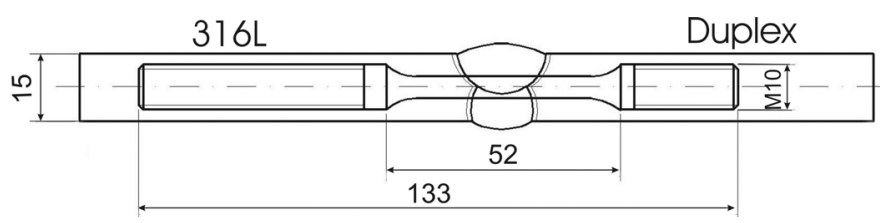

Fig. 6. Specimen for slow strain rate tests

Specimens were immersed in $35 \%$ boiling water solution of $\mathrm{MgCl}_{2}$ at $125^{\circ} \mathrm{C}$ in a specially designed glass chamber, elec- 
trically heated and mounted on tensile testing machine grips. The supplementary tests in an inert environment (glycerin) at $125^{\circ} \mathrm{C}$ were also performed. SSR tests were continued until the specimens failed. Ultimate tensile strength (UTS) and uniform elongation (UEL) were recorded in each test. Reduction of area (RA) at fracture and the energy consumed (En) to failure the specimen were calculated after each test. The results of SSR tests are shown in Table 3 and Figs. 7 and 8.

TABLE 3

Results of SSR tests performed in $35 \%$ boiling solution of $\mathrm{MgCl}_{2}$ and glycerin at $125^{\circ} \mathrm{C}$

\begin{tabular}{|c|c|c|c|c|c|c|}
\hline \hline Specimen & $\begin{array}{c}\text { Environ- } \\
\text { ment }\end{array}$ & $\begin{array}{c}\text { UTS } \\
{[\mathbf{M P a}]}\end{array}$ & $\begin{array}{c}\text { UEL } \\
{[\%]}\end{array}$ & $\begin{array}{c}\text { RA } \\
{[\%]}\end{array}$ & $\begin{array}{c}\text { En } \\
{\left[\mathbf{M J}^{-3}\right]}\end{array}$ & $\begin{array}{c}\text { Cracking } \\
\text { area }\end{array}$ \\
\hline \multicolumn{7}{|c|}{ Base materials } \\
\hline 316L-G & Glycerine & 484 & 43.2 & 81.1 & 174 & \\
\hline 316L & $\mathrm{MgCl}_{2}$ & 463 & 28.1 & 26.9 & 99 & \\
\hline 2205-G & Glycerine $^{2}$ & 628 & 45.2 & 76.0 & 236 & \\
\hline 2205 & $\mathrm{MgCl}_{2}$ & 520 & 23.0 & 39.2 & 88 & \\
\hline \multicolumn{7}{|c|}{ Welded joints } \\
\hline 2Y-G & $\mathrm{Glycerine}^{2}$ & 517 & 28.2 & 77.9 & 124.2 & $316 \mathrm{~L}$ \\
\hline 2Y-Mg1 & $\mathrm{MgCl}_{2}$ & 466 & 14.8 & 27.8 & 41.1 & $2205 \mathrm{HAZ}$ \\
\hline 2Y-Mg2 & $\mathrm{MgCl}_{2}$ & 433 & 17.4 & 30.3 & 59.6 & $2205 \mathrm{HAZ}$ \\
\hline
\end{tabular}

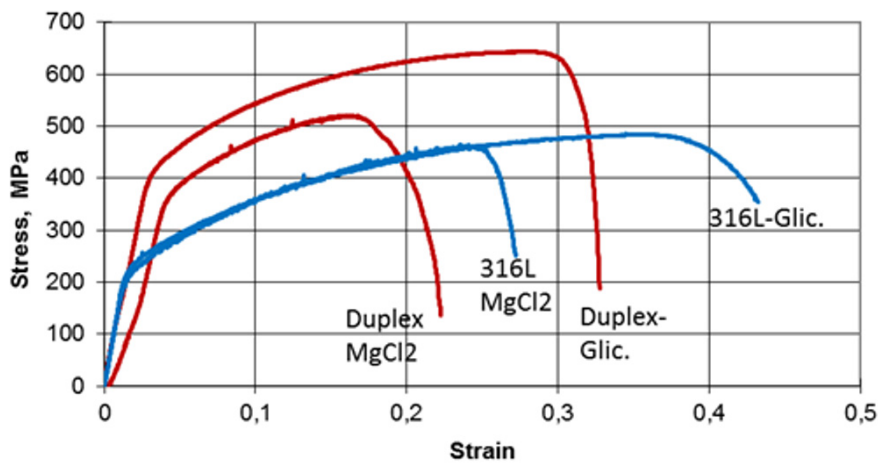

Fig. 7. Stress-strain curves obtained in slow strain rate tests for parent materials; $316 \mathrm{~L}$ and 2205 stainless steels. Tests performed in $35 \%$ boiling solution of $\mathrm{MgCl}_{2}$ and glycerin at $125^{\circ} \mathrm{C}$

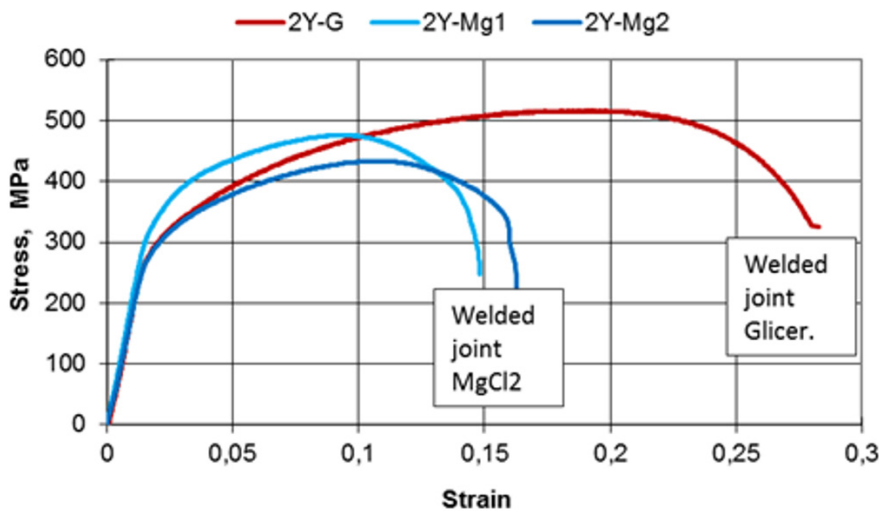

Fig. 8. Stress-strain curves obtained in slow strain rate tests for $316 \mathrm{~L}-$ 2205 stainless steels dissimilar welded joints. Tests performed in $35 \%$ boiling solution of $\mathrm{MgCl}_{2}$ and glycerin at $125^{\circ} \mathrm{C}$
Tests revealed that both, duplex 2205 and austenitic 316L steels are susceptible to stress corrosion in magnesium chloride environment. Plastic properties, but especially reduction in area at fracture zone, decreased significantly after testing in $\mathrm{MgCl}_{2}$ solution. However, dissimilar welded joints showed even greater susceptibility to stress corrosion than parent materials. Macroscopic examinations of SSR samples indicated different breaking points. Samples tested in an inert environment broke in weaker material - on 316L steel side. Samples tested in $\mathrm{MgCl}_{2}$ environment broke on the other side of welded joint - on duplex steel side (Fig. 9).

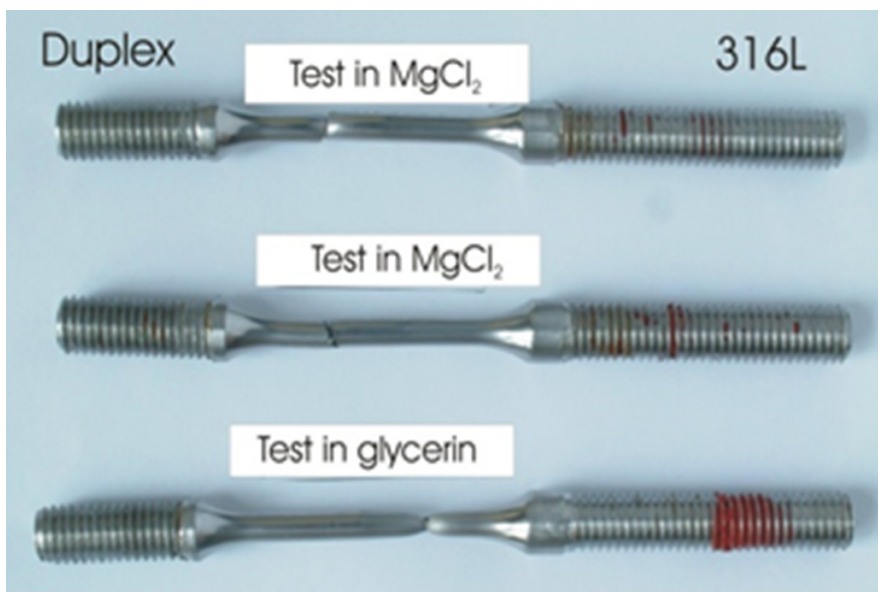

Fig. 9. Samples with welded joints after slow strain rate tests

All samples with welded joints tested in glycerin at $125^{\circ} \mathrm{C}$ shown good plasticity and their fracture surfaces were fully ductile. Samples tested in $\mathrm{MgCl}_{2}$ solution broke in a brittle manner. The fracture surfaces of welded specimens exhibit the brittle or mixed, ductile-brittle character. This alternation of plasticity is a result of stress corrosion cracking phenomena. Detailed microscopic examinations revealed that samples with the welds cracked in the HAZ area between weld and duplex steel parent material at the UTS lower than for 316L steel. Cross sections taken from the fracture area showed that cracks propagate along coarse structure of the heat affected zone of duplex steel (Fig. 10). Cracks were initiated at the austenite-ferrite phase boundaries. The paths of cracks propagation generally proceed along phase boundaries or across ferrite grains. It was noticed that cracks were frequently stopped on elongated, perpendicular austenite grains, or pass them by.

\subsection{Hydrogen assisted stress corrosion cracking}

Slow strain rate testing technique according to EN ISO 7539-7 was also applied to evaluate the susceptibility to hydrogen assisted SCC of investigated steels and their welded joints. Cylindrical specimens with a gauge section of $5.0 \mathrm{~mm}$ in diameter were used. Tests were conducted in synthetic sea water (type A acc. to PN-66/C-06502) with chemical composition given in Table 4. 


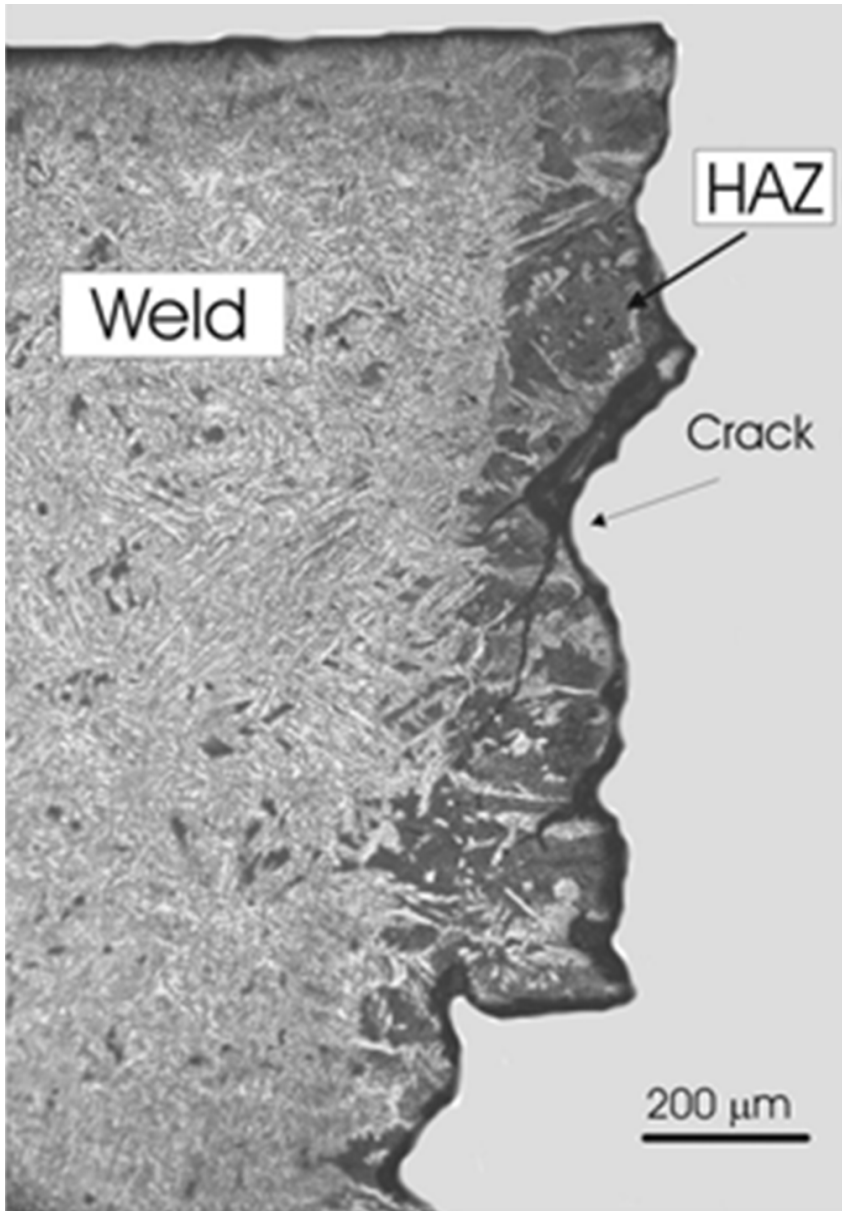

Fig. 10. Crack propagation paths at welded specimen after SSR test in boiling $\mathrm{MgCl}_{2}$ solution at $125^{\circ} \mathrm{C}$

TABLE 4

Chemical composition of synthetic sea water (type A)

\begin{tabular}{|c|c|}
\hline \hline Components & Concentration, $\left[\mathbf{g} \cdot \mathbf{d m}^{-3} \mathbf{]}\right.$ \\
\hline $\mathrm{NaCl}$ & 24.53 \\
\hline $\mathrm{MgCl}_{2}$ & 5.20 \\
\hline $\mathrm{Na}_{2} \mathrm{SO}_{4}$ & 4.00 \\
\hline $\mathrm{CaCl}_{2}$ & 1.16 \\
\hline $\mathrm{KCl}$ & 0.695 \\
\hline $\mathrm{NaHCO}_{3}$ & 0.201 \\
\hline $\mathrm{KBr}_{3}$ & 0.101 \\
\hline $\mathrm{H}_{3} \mathrm{BO}_{3}$ & 0.027 \\
\hline $\mathrm{SrCl}_{2}$ & 0.025 \\
\hline $\mathrm{NaF}$ & 0.003 \\
\hline
\end{tabular}

Hydrogen was introduced into the samples by cathodic current method under galvanostatic condition at room temperature. Samples of parent materials (austenitic and duplex steels) and samples containing welded joints were charged during SSR tests at current density of $10 \mathrm{~mA} \mathrm{~cm}^{-2}$. Such current density was established in previous investigations $[14,15]$ as a critical for hydrogen embrittlement for duplex 2205 stainless steel. The results of SSR tests illustrating the effect of hydrogen charging on the changes of the mechanical properties values are summarized in Table 5 and graphically shown in Figs. 11 and 12.
TABLE 5

Effect of applied cathodic current on the variations of UTS, UEL, RA and En after SSRT in synthetic sea water

\begin{tabular}{|c|c|c|c|c|c|c|}
\hline Specimen & $\begin{array}{c}\text { Cathodic } \\
\text { current } \\
{\left[\mathbf{m A} \cdot \mathbf{c m}^{-2}\right]}\end{array}$ & $\begin{array}{c}\text { UTS } \\
\text { [MPa] }\end{array}$ & $\begin{array}{l}\text { UEL } \\
{[\%]}\end{array}$ & $\begin{array}{l}\text { RA } \\
{[\%]}\end{array}$ & $\begin{array}{c}\mathbf{E n} \\
{\left[\mathbf{M J} \cdot \mathbf{m}^{-3}\right]}\end{array}$ & $\begin{array}{c}\text { Cracking } \\
\text { area }\end{array}$ \\
\hline \multicolumn{7}{|c|}{ Base materials } \\
\hline $316 \mathrm{~L}-1$ & 0 & 579 & 46.7 & 72.1 & 236 & \\
\hline $316 \mathrm{~L}-2$ & 10 & 604 & 54.1 & 48.5 & 278 & \\
\hline $316 \mathrm{~L}-3$ & 10 & 590 & 49.2 & 52.3 & 243 & \\
\hline $2205-1$ & 0 & 722 & 26.9 & 66.4 & 175 & \\
\hline $2205-2$ & 10 & 678 & 10.9 & 18.5 & 62 & \\
\hline $2205-3$ & 10 & 590 & 17.0 & 25.0 & 103 & \\
\hline \multicolumn{7}{|c|}{ Welded joints } \\
\hline $2 \mathrm{Y}-1$ & 0 & 614 & 31.5 & 70.8 & 166 & $316 \mathrm{~L}$ \\
\hline $2 \mathrm{Y}-2$ & 10 & 606 & 24.6 & 45.4 & 124 & $316 \mathrm{~L}$ \\
\hline $2 Y-3$ & 10 & 594 & 23.4 & 53.7 & 117 & $316 \mathrm{~L}$ \\
\hline
\end{tabular}

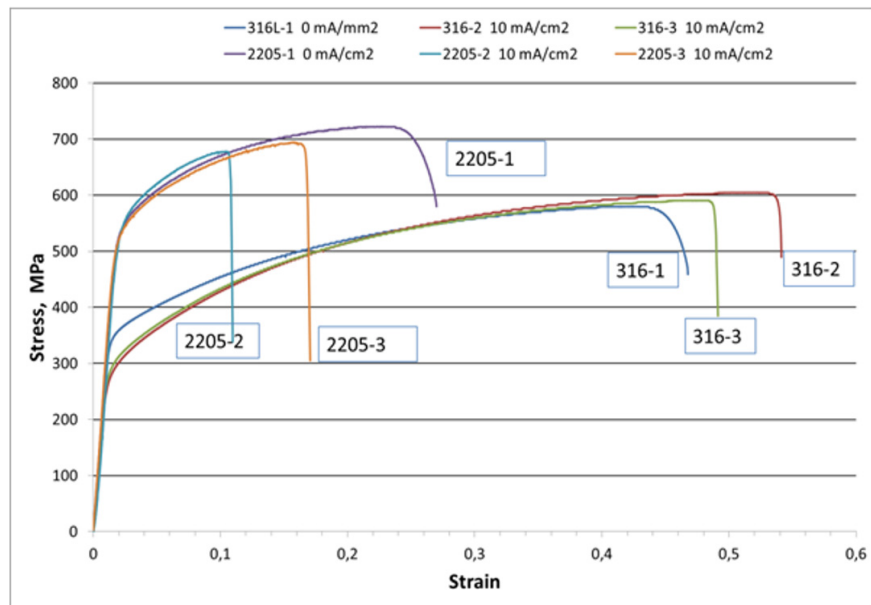

Fig. 11. Stress-strain curves obtained in slow strain rate tests for base materials; 316L and 2205 stainless steels. Tests performed in synthetic sea water under cathodic polarization

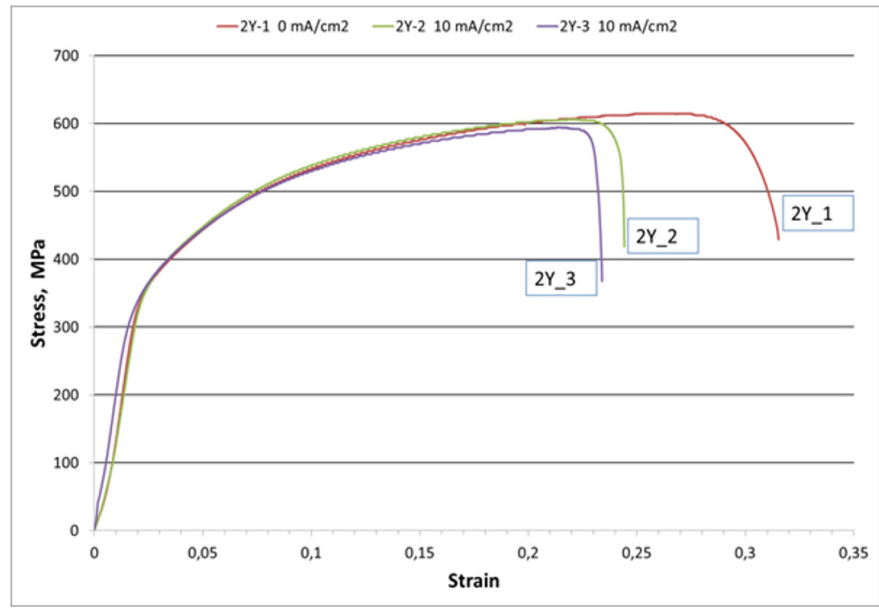

Fig. 12. Stress-strain curves obtained in slow strain rate tests for $316 \mathrm{~L}$ - 2205 stainless steels dissimilar welded joints. Tests performed in synthetic sea water under cathodic polarization 
SSR tests results indicate no significant effect of cathodic polarization on mechanical properties of austenitic, 316L steel samples. Hydrogen charging conditions did not influence the UTS, En and UEL values. However reduction in area (RA) values decreased by $30 \%$ indicating some influence of hydrogen uptake. Such behavior of austenitic steel is not surprising because austenitic stainless steels in general exhibit resistance to HE, but interaction between hydrogen and metastable austenitic stainless steels is a unique case. Hydrogen can facilitate the phase transformation of austenite to martensite, and the martensite phase is suspected to be more susceptible to hydrogen embrittlement. There are many factors which influence the sensitivity of stainless steels to hydrogen interaction: environment, stress, microstructure, and the manufacturing processes. Chemical composition may also play an important role. HE resistance of austenitic steels is highly dependent on the presence of such elements like Ni, Mo and N. These elements improve the resistance to hydrogen damage by stabilizing the austenite phase with respect to the martensitic transformation. Common, less alloyed grades of austenitic steels may suffer from hydrogen. In our study, under test conditions, 316L austenitic stainless steel showed good resistance to hydrogen embrittlement. It may be connected with, relatively short time of hydrogenation.

The susceptibility of 2205 DSS to hydrogen assisted cracking was significantly higher compared to the austenitic stainless steel. Hydrogen charging caused reduction in plastic properties and only slightly affecting the value of UTS. It was recorded almost twofold decrease in elongation of hydrogen charged samples and a significant decrease in RA values.

Such behavior of parent materials indicates the possibility of increased susceptibility to hydrogen embrittlement of their welded joints. This phenomenon may be enhanced by unfavorable microstructure of the weld metal and heat affected zone. HAZ from the duplex steel side contain larger portion of ferrite in relation to duplex steel. Moreover, there is a danger of precipitation of intermetallic phases at weld area that may cause a greater degree of susceptibility to hydrogen embrittlement.

Slow strain rate tests results have not confirmed this assumption. It was found that all samples with dissimilar welded joints cracked at the material of lower strength, in the area of $316 \mathrm{~L}$ stainless steel. Hydrogenation did not result in reduction in UTS of duplex steel, weld metal or HAZ from the duplex steel side, below the tensile strength for austenitic steel. It should be noted, however, that the time of hydrogenation was relatively short and equal to SSR tests duration (about 60 hours).

\section{Conclusions}

The following conclusions can be drawn from the present study:

1. The study of dissimilar duplex 2205 and austenitic AISI 316 steels welded joints indicated the harmful effect of the welding heat input on microstructure and corrosion resistance of the joint. The narrow heat affected zone on the duplex steel side proved to be the most susceptible to stress corrosion acting on the whole joint when testing in $35 \%$ boiling solution of $\mathrm{MgCl}_{2}$ environment. Rapid propagation of corrosion cracks in HAZ resulted in reduction of materials strength below UTS of austenitic stainless steel and causing the breakdown of the sample in this area. It should be noted that the applied corrosive environment of $\mathrm{MgCl}_{2}$ is very aggressive and it is not commonly used in industrial practice. The study indicates the need for testing the duplex steel welded joints before exposure to a variety of chemical environments.

2. Increased susceptibility of duplex steel HAZ to stress corrosion cracking results from unfavorable microstructure of this ferrite-rich area. Multi-run welding with the use of less heat input can improve the corrosion resistance of the joints. This observation, however, requires further investigations.

3. Hydrogen charging resulted in a significant decrease in plasticity of the duplex steel while austenitic $316 \mathrm{~L}$ steel remained almost impervious to such impacts. For this reason dissimilar welded joints of austenitic 316L and duplex 2205 steels are at risk of hydrogen assisted SCC. Slow strain rate tests of dissimilar welded joints under cathodic polarization did not show significant weakness of austenite-ferritic welds and HAZ at duplex steel side. Welded specimens also broke at austenitic steel area, hence reduction in ductility of these zones must be expected.

\section{REFERENCES}

[1] R.N. Gunn, Duplex stainless steels - microstructure, properties and applications, Woodhead Publishing Ltd, Abington (2003).

[2] G. Chai, M. Andersson, Proc. Eng. 55, 123-127 (2013).

[3] C. Messner, V.V. Silberschmidt, E.A. Werner, Acta Mater. 51, 1525-1537 (2003).

[4] J. Łabanowski, A. Świerczyńska, S. Topolska, Pol. Marit. Res. 21 (4), 108-112 (2014).

[5] S. Topolska, J. Łabanowski, Mater. Tehnol. 49 (4), 481-486 (2015).

[6] G. Straffelini, A. Molinari, F. Bonollo, A. Tiziani, Mater. Sci. T. 17 (11), 1391-1397 (2001).

[7] M.C. Young, S.L.I. Chan, L.W. Tsay, C.-S. Shin, Mater. Chem. Phys. 91 (1), 21-27 (2005).

[8] C. San Marchi, B.P. Somerday, X. Zelinski, X. Tang, G.H. Schiroky, Metall. Mater. Trans. A 38A, 2763-2775 (2007).

[9] L. Karlsson, S. Rigdal, S. Anderrson, Welding in the World 39, 99-110 (1999).

[10] J. Nowacki, P. Rybicki, Journal of Achievements in Materials and Manufacturing Engineering 17, 113-116 (2006).

[11] W. Zheng, D. Hardie, Corros. Sci. 32 (1), 23-26 (1991).

[12] T.P. Perng, C.J. Altstetter, Metall. Trans. A 18A, 123-134 (1987).

[13] R.A. Perren, T. Suter, C. Solenthaler, G. Gullo, P.J. Uggowitzer, H. Böhni, M.O. Speidel, Corros. Sci. 43, 727-745 (2001).

[14] F. Zucchi, V. Grassi, C. Monticelli, G. Tabanelli, Corros. Sci. 48, 522-530 (2006).

[15] P. Váňová, J. Sojka, METABK 53 (2), 163-166 (2014). 